\title{
Jaime Jaramillo Uribe: la historia, la pedagogía y las ciencias sociales*
}

Jaime Jaramillo Uribe: History, Pedagogy and Social Sciences

Jaime Jaramillo Uribe: História, pedagogia e ciências sociais

Martha Cecilia Herrera** (iD orcid.org/0000-0003-4170-7822 Carlos Low*

\section{Entrevista}

Revista Colombiana de Educación, N.⒎ Segundo semestre de 2016, Bogotá, Colombia.

Para citar: Herrera, M. C., y Low, C. (2016). Jaime Jaramillo Uribe: Ia historia, la pedago-

gía y las ciencias sociales. Revista Colombiana de Educación, (71), 401-414. 
aime Jaramillo Uribe nació en Abejorral (Antioquia) en 1917. Recibió el título de licenciado ${ }^{1}$ en Ciencias Económicas y Sociales por la Escuela Normal Superior de Bogotá en el año 1941, y el de doctor en Derecho y Ciencias Políticas por la Universidad Libre de Colombia; cursó estudios en la Universidad de la Sorbona en París. Fue profesor titular de la Universidad Nacional de Colombia, decano de la Facultad de Filosofía y Letras y director del Departamento de Historia; profesor de la Universidad de los Andes y decano de la Facultad de Filosofía y Letras; profesor visitante en las Universidades de Hamburgo, Vanderbilt, Oxford y Sevilla, fundador del Anuario de Historia Social y de la Cultura, director de la revista Razón y Fábula y director científico del Manual de historia de Colombia (Colcultura, 1978). Publicó numerosos artículos en revistas nacionales y extranjeras. Escribió entre otros los siguientes libros: El pensamiento colombiano en el siglo xIx (1964), Ensayos de historia social colombiana (1969), Historia de la Pedagogía como historia de la cultura (1970), Antología del pensamiento político colombiano (1970), La personalidad histórica de Colombia y otros ensayos (1977). En el año de 1993 el presidente de la República, Cesar Gaviria, le otorgó la Cruz de Boyacá, el máximo galardón nacional, en honor a los múltiples servicios prestados al país en el campo de la docencia y la investigación histórica.

Esta entrevista forma parte de una serie realizada a profesores como Ernesto Guhl, Virginia Gutiérrez y Roberto Pineda Giraldo, protagonistas del pensamiento social en el siglo xx en Colombia. Constituye parte del archivo oral sobre "Los intelectuales académicos en Colombia" que los autores realizaron para la Universidad Pedagógica Nacional. Dentro de esta línea surgió la investigación en torno a la Escuela Normal Superior, financiada por Colciencias y por la Universidad Pedagógica Nacional (Véase: Los intelectuales y el despertar cultural del siglo, el caso de la Escuela Normal Superior. Una historia reciente y olvidada. Santafé de Bogotá, UPN, Imprenta Nacional, 1994, I54p).

P. Profesor Jaime Jaramillo, podría decirnos ¿cuál era la situación de las ciencias sociales y humanas en la década del treinta, época en la cual usted empieza a formarse como historiador?

J. J. U. En esta época aparecen algunas formas nuevas de abordar los temas que podían interesar a este tipo de disciplinas, aunque también se continúa haciendo trabajos a la manera tradicional. Por ejemplo, en el caso de la historia lo que hacía Gabriel Giraldo Jaramillo era muy tradicionalista, seguía de cerca las orientaciones de la Academia Colombiana de Historia. Aunque Gabriel, como discípulo que fue del Instituto Etnológico Nacional, anexo a la Escuela Normal Superior, se empapó un poco de las

1 N. de las e. Se hicieron algunas modificaciones a la semblanza del profesor Jaramillo Uribe incluida en la entrevista original, para actualizarla. 
nuevas tendencias y enfoques, no tenía sin embargo una formación especializada, era un abogado que trabajaba la historia tradicional. El caso de Antonio García era el de la gente de nuestra generación que empezó a ponerse en contacto con el marxismo, contacto que nos llevaba a la idea de que había que estudiar a Colombia con base en las ciencias económicas; pero el mismo García hasta ahora se iniciaba en los estudios marxistas, en los estudios económicos, apenas había terminado su carrera de Derecho en Popayán, pero representaba un elemento innovador desde ese punto de vista.

p. Cuando se miran las proyecciones de la Escuela Normal Superior en los campos de las ciencias sociales y humanas, se encuentra cómo los etnólogos y los antropólogos reconocen que esta institución fue un eslabón clave en el proceso de institucionalización de estas profesiones; se ve que ellos encuentran sus raíces en la Escuela Normal Superior. En el caso de la historia cabe entonces la pregunta, ¿por qué no emergió de allí un núcleo sólido de intelectuales dedicados a hacer historia? Pues sabemos que en la ENS también hubo profesores de historia destacados como José María Ots Capdequi y Gerhard Masur.

¿A qué podemos atribuir este hecho, por qué es usted de las pocas personas egresadas de la institución que se dedicó al cultivo de la historia?

J. J. U. Eso pudo deberse a circunstancias un poco fortuitas. En la licenciatura de Ciencias Sociales nosotros tuvimos clases de etnografía y etnología, tuvimos como profesor al alemán Justus Wolfram Shottelius que nos había enseñado una parte de ambas y entusiasmó a la gente, ya que los sacaba a exploración a los santanderes para estudiar la cultura Guane. Por su parte el francés Paul Rivet traía la tradición francesa de la antropología y de la etnografía como disciplinas que se ocupaban de las culturas indígenas del pasado y contemporáneas. Rivet no trajo aquí la noción de la antropología social moderna que se introdujo unos años más tarde por la influencia de las escuelas norteamericanas. La presencia de Rivet con su aureola y prestigio de sabio (además contaba con el apoyo del presidente Eduardo Santos), así como la fundación del Instituto Etnológico atrajo a un grupo importante de estudiantes; a mí no me atrajo por un problema de sensibilidad personal. Me interesaban la sociología y la historia, la sociedad moderna y tenía además mucho interés por la política. Fui un estudiante políticamente activo, me matriculé en la izquierda y casi desde los primeros años me interesó mucho la literatura socialista y el marxismo. Naturalmente eso me llevaba a tener interés por la sociedad contemporánea, por la sociedad moderna.

A mí me interesaba el país de ese tiempo, el país que se estaba desarrollando, no me interesaba la etnografía para dedicarme a ella sino de manera secundaria. A mí me interesó la historia desde el principio entre otras cosas porque me di cuenta de la pobreza de la historiografía nacional. 
Yo empezaba a tener muchas lecturas: literatura socialista; marxismo y economía y sabía que aquí no existía historiografía nacional y que no se había hecho la historia nacional; entre otras cosas porque creía que la historia que había que hacer era de tipo social y económico. Entonces probablemente eso fue lo que me llevó a los temas históricos, a diferenciarme de mis demás compañeros quizá porque no tenían el interés político que tenía yo.

P. Un grupo de egresados atribuye a la Escuela Normal Superior un gran peso en su formación, ¿usted le daría mucha importancia o matizaría esta influencia?

J. J. U. A mí me apasionó mucho la historia desde la época de la Escuela Normal Superior. Allí se contó con los aportes de Rudolf Hommes de Gerhard Masur, profesores que se movían en el plano de la historia política y contemporánea, pero realmente esto no representaba un elemento de peso, lo suficiente como para haber formado un grupo de discípulos, era una cosa de menor envergadura. Creo que en mi caso fueron más decisivas las influencias que venían de fuera que las que venían de dentro de la Normal, aunque debo reconocer que la insistencia que en ella se hacía de volcar nuestro interés hacia la cultura nacional, hacia los problemas del país, también me afectó significativamente. Por estos años empecé a leer las cosas que se escribían en el país sobre historia y me di cuenta de la pobreza existente en la mayoría de los trabajos, a la vez que corroboré mi entusiasmo por la política, por la economía; reconozco que en esto le debo mucho al marxismo, pues fueron las lecturas de Marx las que me llevaron a interesarme en la historia social y económica, lo mismo que a Antonio García, Darío Mesa y muchos otros.

P. ¿Por qué a pesar de su entusiasmo por las ideas marxistas, no se ve una aplicación directa de estas en sus primeros escritos históricos?

ı. J. u. Sí, yo reconozco que le debo mucho al marxismo como estímulo intelectual, pero nunca fui muy ortodoxo, siempre tuve contacto con autores que no tenían puntos de vista ortodoxamente marxistas. Mi paso por París me afianzó más en esa idea de ampliar el horizonte de lecturas, de autores, de escuelas de pensamiento, de manera que muy pronto mi formación fue relativamente ecléctica. Cuando empecé a escribir y a hacer investigación, ya operaba con conceptos y categorías que podían ser marxistas pero también con conceptos y categorías de otras escuelas, de otras tendencias; tenía y sigo teniendo una visión mucho más amplia.

p. Cuando uno habla del ambiente propicio que existió en la Escuela Normal Superior para el cultivo de las disciplinas humanas y sociales, es inevitable preguntarse, ¿por qué este proyecto prácticamente abortó en la década del 50 bajo los gobiernos conservadores? Algunos de sus egresados nos han dicho que en estos años fueron víctimas de un ambiente de persecución. ¿Usted cree que esta puede ser una visión un tanto exagerada, se dio o no persecución? 
נ. ı. U. En los años de 1946 a 1953, sí hubo persecución y bastante discriminación. Incluso a mí no me dieron trabajo en la Escuela Normal Superior por esos años. El rector, el poeta Rafael Maya, estaba haciendo en ese momento política en la Normal y estaba tratando de conservatizarla; el gobierno de turno decía que esa era una casa de comunistas y de subversión nacional. En la creación de ese ambiente hostil participó el periódico El Tiempo, Calibán escribía semanalmente contra la Escuela y hablaba contra los comunistas de la Escuela y la necesidad de cerrarla. Indudablemente sí hubo ambiente adverso y en cierto sentido persecución, eso naturalmente tuvo sus matices que fueron definidos muchas veces por personas que estaban en la dirección.

Creo además que el traslado de la Escuela Normal Superior para Tunja, una de las primeras decisiones administrativas del gobierno de Laureano Gómez, se debió a la necesidad de cambiar su orientación y de salir de gente que no agenciaba los propósitos de los gobernantes conservadores; se quería definitivamente convertirla en otra cosa. El traslado se debió también a un problema muy típico colombiano, relacionado con asuntos de política regionalista y era que probablemente el ministro de Educación, que en ese momento era Rafael Azula Barrera, les había hecho la promesa a los boyacenses de que volvería a llevar la Facultad de Ciencias de la Educación a Tunja y que Ilevaría la Escuela Normal Superior como núcleo de esta y de una futura universidad.

P. Pero, ¿qué era realmente lo que hacía que algunos sectores de la sociedad vieran a la Normal como comunista? Todos los egresados y exprofesores con quienes hemos hablado coinciden en que en la ENS existía un espíritu de tolerancia frente a todas las formas de pensamiento y afirman que en ningún momento los profesores hacían adoctrinamiento político ni nada por el estilo.

J. J. u. Sí, pero se creía que había profesores que hablaban de materialismo histórico, de lucha de clases y de Marx; que había además estudiantes que militaban en el Partido Comunista, Socarrás mismo tenía una aureola de izquierdista, de peligroso. Naturalmente había gente por dentro de la ENS, alumnos y probablemente también profesores, que se asustaban alrededor de esas cosas y entonces en un momento de lucha política y de violencia, había gente que veía en la ENS un gran peligro. Estudiantes de mentalidad muy conservadora y muy clerical, Ilevaban rumores hasta el gobierno, a los directores políticos y a la Embajada Americana. La prensa desató una campaña de hostilidad, abanderada por los periódicos conservadores EI Siglo, La República e incluso los liberales (El Tiempo), porque no hay que olvidar que había sectores liberales reacios a cualquier tipo de reforma, a confrontarse con otros tipos de pensamiento. De manera que en ciertos sectores de la opinión pública se fue formando el consenso de que ese era un foco de formación de gente peligrosa. 
P. A raíz de los sucesos del 9 de abril de 1948, el gobierno conservador y sectores de la jerarquía eclesiástica inculpan a los estudiantes y profesores de la Escuela Normal Superior de muchos de los desmanes sucedidos en la capital, ¿cómo ve esto?

ı. ı. U. Sí, en parte estas acusaciones se dieron, en especial a través de la prensa, porque además nos cobijó la campaña contra la Universidad Nacional, que estaba regida por Gerardo Molina. Es decir, la prensa conservadora toda y parte de la liberal coincidían en muchas cosas y no hay que olvidar que era un momento muy conflictivo de la vida del país, la política sindical era muy beligerante, era época de huelgas obreras, conflictos agrarios, violencia partidista. El otro aspecto que incidió se relaciona con la presencia en la Escuela Normal Superior y en la Universidad Nacional, de profesores emigrados de la España republicana, durante el período de la guerra civil, motivo por el cual la prensa conservadora enfiló todas sus baterías contra esas instituciones con el propósito de hostigar a los emigrados. Ninguna de esas personas era comunista, ni marxista, ni nada, eran simplemente gentes de mentalidad liberal y de mentalidad científica moderna. Ni Ots Capdequi, ni García Banús, ni González de la Calle, ni Cirre, ninguno de ellos era comunista ni anarquista; eran republicanos españoles, pero como en ese momento republicano y rojo eran lo mismo, toda la prensa conservadora hablaba de los rojos en la Escuela Normal Superior y en la Universidad Nacional.

P. Los exilados republicanos, los españoles transterrados se organizaron en Bogotá, ¿ recuerda algo al respecto?

ı. J. u. Yo sé que en Bogotá españoles republicanos tenían una sede, me parece que en Teusaquillo, donde se reunían de manera fraternal; el doctor Trias, Prats, Ots Capdequi, Trillas, Ios Recasens, algunos periodistas, en fin, los pocos emigrados, porque desafortunadamente al país no vinieron sino 20 o 30, si hubieran llegado siquiera 500 o 1.000, su aporte en la cultura colombiana habría sido importantísimo. Lo lamentable es que el país no hubiera aprovechado esta situación para haber traído una gran inmigración de académicos y científicos españoles y alemanes, como sí lo hicieron México y Argentina. Por ejemplo, la migración española republicana en México transformó totalmente las condiciones culturales; ellos crearon allí una gran industria editorial, el Colegio de México, y en fin, un poco de instituciones importantes, las grandes publicaciones del Fondo de Cultura Económica, ellos transformaron la cultura de México. Aquí llegaron pocas personas y su labor lamentablemente no tuvo continuidad, ya que cuando vino el cambio político de 1946 todos se fueron a otros países.

P. En el archivo de la Escuela Normal Superior encontramos unos formatos de fichas de seguimiento de la práctica docente, una especie de radiografía de los estudiantes, en donde el profesor debía anotar cómo se

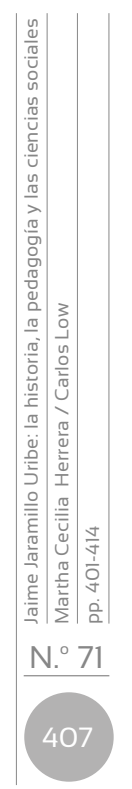


vestían, cómo dominaban el grupo, cómo hablaban; usted que fue director de práctica, ¿qué nos puede comentar sobre este punto?

ı. ı. u. Claro, entre otras cosas yo ayudé a formar esas guías con la siguiente idea: se partía de la base de que enseñar tenía dos partes, una relacionada con los conocimientos y otra con la pedagogía, con la práctica docente. Siempre les decía a los estudiantes, miren, el éxito de un profesor depende primero, del dominio de la materia, si usted no se presenta dominando su materia y no prepara bien sus clases, está perdido, no hay pedagogía ni hay nada que le mantenga la disciplina de los estudiantes; segundo, hay que recurrir a ciertos trucos, por ejemplo no comiencen nunca la clase si los estudiantes no están sentados, haga que alineen los pupitres en formas horizontales y verticales; porque era una cosa horrible y en eso sufrían los pobres tipos y veía uno la gente fracasar en lo que Ilamamos la pedagogía del dominio del grupo. Les recalcaba que la voz es una cosa muy importante, si usted habla muy duro los estudiantes se le aturden, tiene que hablar con modulaciones, despacio y en voz más bien baja, cosas de ese estilo. Socarrás insistía en la idea de que a la gente no había que enseñarle demasiadas cosas sino formarle hábitos y en eso creo que tenía toda la razón. Hay que enseñarle a caminar, a hablar y a mover las manos; no se trata tanto de aritmética y de gramática sino que a esta gente hay que enseñarle ciertas actitudes.

Cuando se llegaba a ese problema de la dirección del grupo y de la autoridad del maestro se decía: es necesario que adquiera ciertos hábitos, que infunda cierto respeto, cierta admiración, se insistía mucho en todo eso. Por una parte en las técnicas de conducción del grupo y luego en la conducta y el manejo del profesor. En las fichas que ustedes mencionan, se calificaba la preparación de clase, el dominio del grupo y la presentación personal. Se creía que el maestro debía ir afeitado, limpio y bien vestido exigencias que hoy han caído en desuso, pero ello obedecía a los patrones de la época y probablemente a herencias de una concepción elitista de la pedagogía. A cada practicante de la Normal se le llevaba una ficha en la que se registraban no solo sus calificaciones, sino también sus características personales y sus condiciones externas.

P. José Francisco Socarrás, uno de los rectores "estrella" de la Escuela Normal Superior, nos ha hablado que en las clases se seguía el método de proyectos de John Dewey, irecuerda algo de eso?

נ. ı. u. Sí claro, se trató de funcionar sobre la base del método de proyectos, pero eso se aplicó a medias porque el método es difícil y la gente no estaba preparada ni tenía experiencia en ese campo. Este tipo de influencia venía desde la Escuela Normal Central, cuya dirección la asumieron personas como Alfonso Jaramillo, que se habían formado en la Escuela Nueva, las enseñanzas del Gimnasio Moderno y Ovide Decroly. Algunos de ellos, como Jaramillo, habían ido a Ginebra y estudiaron con 
Piaget y Ferriére y trajeron los métodos de los centros de interés y de proyectos. Nosotros tratábamos de aplicar en la escuela primaria el método de los centros de interés y en la escuela secundaria y en la normal el método de proyectos. Por ejemplo, en las ciencias sociales el proyecto era el café y en torno a él se estudiaba la geografía, la historia, la economía, sin embargo, eso no tuvo un desarrollo muy consistente; a pesar de que se hacía el intento de reunir a los profesores de las tres disciplinas a fin de coordinar la enseñanza de un tema.

P. Y con respecto a los cursos que se denominaban seminarios, ¿qué nos podría decir? ¿Llegaron a ser muy rigurosos desde el punto de vista académico?

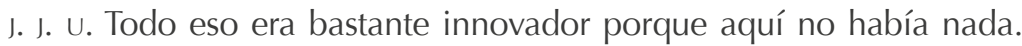
Aquí la universidad funcionaba en unas casas viejas donde había unas bancas y la gente iba a oír a unos abogados que hacían discursos, no había bibliotecas, no había profesores de tiempo completo, no había secretarias, no había nada. Por eso la Escuela Normal Superior fue algo excepcional por todas las circunstancias. Tenía biblioteca, laboratorios, gabinetes. La misma magnitud de la escuela permitía hacer el ensayo porque no había muchos estudiantes, unos 150, y por cada promoción de esas cuatro especialidades había más o menos unos 40 alumnos. Allá existía una concepción distinta de lo que debía ser una institución de enseñanza y entonces se hicieron ensayos de ese tipo, que no eran muy consistentes pero sí muy innovadores con respecto a lo existente, que era lamentable en la época. La Universidad Nacional que era la más consistente vino a hacerse una universidad en el sentido moderno después de 1936, a partir de la reforma de López Pumarejo, antes era una serie de facultades dispersas, las únicas que tenían más o menos solidez eran medicina e ingeniería, porque tenían gabinetes y unos laboratorios y porque imperiosamente tenían que hacer algo con las manos. Las facultades de Derecho eran unos salones donde se sentaban los muchachos a oír conferencias, a escuchar discursos.

P. ¿Cómo fueron las clases de sociología que usted dictó en la Normal Superior?

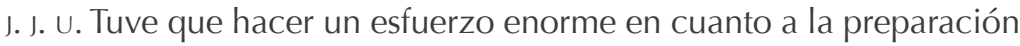
del curso de sociología que dicté en la Normal. Tenía que estudiar y hacer lecturas de 6, 7 y 8 horas diarias, porque aquí no había nada sobre este campo. A nosotros no nos habían preparado para eso; no habíamos tenido un curso de sociología moderna en la Normal. Empecé a preparar este curso con autores como Armand Cuvíllier, un sociólogo francés hoy en día muy olvidado, y posteriormente, cuando entré a la Universidad Nacional dicté un curso con mayor rigor, más dirigido a lo que ha sido la sociología moderna, en donde abordaba temas relacionados con teoría de los grupos, las adaptaciones y los conflictos sociales. Creo que lo que se Ilamaba antes aquí Sociología era apenas una historia de las doctrinas 
sociales, comenzando por Comte y Spencer. Probablemente no pasaba de ahí, del pensamiento social del siglo xix. No se trataba de sociología en el sentido estricto de una disciplina que permite estudiar la sociedad contemporánea.

Como he dicho, la Normal comenzó a hacer una serie de innovaciones, por ejemplo, eso de los trabajos de investigación para los cursos, buenos o malos, fue algo de gran valor, a la gente había que ponerla a hacer algo propio, y algo tenía que salir de ahí, por lo menos algunos hábitos. Era muy importante inculcarle a la gente la idea de que su aprendizaje no dependía solo de lo que le suministraba el profesor, sino que había otras vías de aprendizaje en las que debía incursionar. De manera que la Escuela Normal Superior jugó un papel significativo, a pesar de su disolución en 1951, pues siempre quedó la semilla en otras partes, esa semilla pasó al Instituto Caro y Cuervo, al Instituto de Antropología y a la Universidad Nacional.

P. ¿En qué año empezó a escribir usted ensayos históricos?

ı. ı. U. Empecé propiamente a hacer investigaciones en mis años de la Escuela Normal Superior a escala muy simple. Como dije, la ENS entre otras innovaciones, familiarizó a los estudiantes por lo menos con la etapa más elemental de la investigación, que era ponernos trabajos y hacernos consultar una bibliografía, porque ni siquiera eso se hacía en las universidades colombianas. Las universidades funcionaban sobre la base de las conferencias que dictaban los profesores y lo que los estudiantes hacían era preparar sus cursos con esas conferencias, pero no había una búsqueda bibliográfica personal. Recuerdo que Antonio García nos ponía a estudiar el café, el banano y la colonización cafetera de Antioquia y teníamos que ir a buscar geografías viejas, memorias de la Contraloría, informes del Ministerio de Industria y cuadros estadísticos. Entonces esa fue la primera aproximación a eso llamado investigación.

Posteriormente cuando regresé de Europa y me vinculé como profesor en la Universidad Nacional, me di cuenta de que había que hacer investigación histórica sobre la base de las fuentes primarias, de los archivos, sobre todo al percatarme de la pobreza de la historia colombiana. En un primer momento me orienté por la historia colonial y entonces fue por esa época cuando se fundó el Departamento de Historia de la Universidad Nacional, el cual comenzó de manera modesta, con 2 o 3 profesores. Fue en esos años cuando me metí al Archivo Nacional e inicié una investigación que luego dio como resultado mis primeros ensayos en historia social que trataban sobre la esclavitud, el mestizaje, la población indígena, y puede decirse que ahí fue cuando empecé a hacer investigación en el mejor sentido de la palabra. Eso fue más o menos entre 1958 y 1962. En esa misma época comencé el estudio de la historia de las ideas, la historia del pensamiento, que también era un campo que me interesaba mucho y estaba completamente inexplorado en el país. 
P. En esos años, ¿con quién intercambiaba usted sus inquietudes intelectuales? Virginia Gutiérrez y Roberto Pineda nos cuentan que tenían un grupo para discutir los trabajos, en su caso, ¿en cuál núcleo interactuaba?

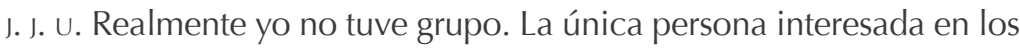
estudios sociales era yo. Con el grupo que mencionan siempre conservé una amistad, entre otras cosas porque fui profesor de Virginia y de Roberto y Darío Mesa. Ellos entraron a la Escuela Normal Superior cuando yo estaba terminando. Formaron un núcleo muy apretado en torno a Paul Rivet, a la etnografía y la antropología. En mi caso la única persona que se interesó por la historia fui yo, entonces no tuve grupo. A ellos el funcionamiento en torno a Rivet y al Instituto Etnológico les dio un sentido más de escuela y de grupo. Yo siempre estuve solo y nadie tenía interés en ese tipo de historiografía y de investigación histórica que yo consideraba se debía hacer. Tengo que agregar además que los que después se dedicaron a hacer historia, la primera generación de historiadores en sentido estricto, todos fueron discípulos míos.

P. ¿Su interés por la historia encuentra entonces continuidad en sus discípulos?

J. J. u. Sí, así es, la generación que me siguió y que fueron historiadores profesionales, todos fueron discípulos míos y egresados de la Universidad Nacional, Jorge Orlando Melo, Germán Colmenares, Margarita González, Hermes Tovar, entre otros. Inicialmente eran muy pocos. Una escuela se va formando con base en 2, 3, 4 personas, hoy puede haber 10 o 15, y quienes ahora empiezan a surgir en el campo de la Historia, son discípulos de ese primer núcleo de intelectuales.

En la Universidad Nacional y en uno de esos cursos que se daban en las facultades de ese tiempo, hubo un profesor español Ilamado Antonio Antelo que dejó también cierta semilla en este campo. Antelo tenía muy buen criterio y era un historiador formado; los profesores de historia en la Facultad de Filosofía éramos él y yo. El entendía mucho a la gente y la puso en contacto con un tipo de historiografía nueva, no tenía interés en la historia colombiana sino en la historia española, en la historia general, pero tenía una orientación moderna y creo que estimuló mucho al estudiantado con las buenas clases de historia; aquí hizo una carrera universitaria muy buena y regresó a España.

P. Nos gustaría que comentara sus acercamientos al campo de la Historia de la Educación, usted tiene dos textos sobre ese tema. ¿A partir de qué momento se interesó en el problema de la educación?

ı. .. u. Yo siempre me interesé por la historia de la educación, de las ideas, y siempre pensé que la historia de la educación era una historia que era necesario fomentar como parte de estas áreas. Yo hice por ahí un escarceo que se llama Historia de la pedagogía como historia de la cultura, el cual resultó de una situación completamente circunstancial. Cuando 
era profesor de la Universidad Nacional en el año 1952, en la Facultad de Filosofía, siendo decano Cayetano Betancur, surgió la idea de introducir un curso de Historia de la Pedagogía que no estaba en el plan de estudios, pues se aspiraba a que los licenciados de la Nacional tuvieran acceso a la docencia y al escalafón de la enseñanza secundaria. Para esto se exigía como requisito haber hecho unas prácticas y algunos cursos de Pedagogía, motivo por el cual se pensó en hacer algunas modificaciones e introducir este curso. Entonces me dijo Cayetano, tú que vienes de la Escuela Normal Superior y que viste allá Historia de la Pedagogía, por qué no haces este curso, y así se dio; fue así como unas alumnas tomaron apuntes de las lecciones que dicté, luego los revisé y después sirvieron de base para la publicación, que entre otras cosas ha tenido ya varias ediciones. Es un libro que se sale un poco de los moldes tradicionales de las historias de la pedagogía, yo le mezclaba mucho la historia social y económica de Europa, les trataba de mostrar el vínculo entre el cambio de los sistemas pedagógicos y las necesidades sociales e industriales; mostrarles que eso no sucedía simplemente como resultado de unas ideas sino que dependía también de ciertas exigencias de la vida social.

P. ¿Cómo surgió el texto sobre "El proceso de la educación del virreinato a la época contemporánea"?

ı. ı. U. Ese ensayo lo hice porque necesitábamos introducir en el Manual de historia de Colombia un capítulo sobre el tema. En el plan que presenté como director del Manual, incluí un capítulo que se refería a la educación, al igual que consideré que debía existir un capítulo referente a la economía, a la administración del Estado y a las artes. Tratábamos de hacer una especie de visión global de la historia de Colombia y, sobre todo, darle importancia a aquellos temas que habían sido ignorados por la historiografía tradicional. Aquí a ningún historiador se le había ocurrido hacer una historia del arte, ni una historia de las ideas filosóficas, ni siquiera la historia de la literatura en un sentido moderno. La historiografía nacional vivía dependiente de la historia de Gómez Restrepo y del padre Segura. Revisando la historia del país que sigue teniendo tan poca gente, no encontré quién hiciera la historia de la educación y decidí hacerla yo mismo. Fue así como apoyado en datos que tenía de mis exploraciones sobre otros temas - ya que siempre hice alusión a la educación en mis trabajos—, decidí hacer ese pequeño ensayo que era lo único factible, porque también estábamos limitados pues esas monografías no podían tener más de 40 o 50 páginas. Después se han hecho otros trabajos y la cosa progresa. En la Universidad Pedagógica se han hecho varios de ellos, y hay un esfuerzo serio y continuo por avanzar en este campo.

P. En una publicación sobre la investigación en Colombia, hay un ensayo de Jorge Orlando Melo sobre la historia y cuando se refiere a la historia de la cultura dice que ha tenido pocos desarrollos en el país y casi 
todos en el campo de la historia de la educación, refiriéndose en especial a los resultados del proyecto interinstitucional de las prácticas pedagógicas que tiene como enfoque a Foucault, ¿qué opina de esa afirmación?

ı. ı. u. Yo creo que es cierta, y es justa. La historia de la cultura en nuestro país ha tenido muy poco desarrollo. Es que nuestro movimiento historiográfico, ya de manera seria, es muy reciente y cuenta con muy pocos representantes. Ahora, esos pocos se han dedicado más a la historia social y a la historia económica y muy pocas personas se han interesado en la historia de la cultura, motivo por el cual hay mucho por explorar en este campo. Se han hecho algunas cosas en historia del arte, pero falta mucho, lo único que se ha trabajado como dice Melo es la historia de la educación y de las instituciones educativas con sus limitaciones, pero lo que los europeos -los franceses y los alemanes- Ilaman historia de la cultura, ha tenido escasos desarrollos acá, que se pueden contar en los dedos de la mano. Falta hacer estudios de la historia de las ideas, historia del pensamiento, lo que los franceses Ilaman historia de las mentalidades, apenas se está comenzando. Además, en la historia de la cultura, falta mucho por hacer, no hay estudios sobre la historia de la cultura colonial con excepción de uno que otro estudio literario, tampoco del siglo xIX, ni de la época reciente; ha habido por ahí un intento de Carlos Uribe Celis sobre Los años veinte en Colombia, que es una especie de entrada, de esfuerzo por captar algunos aspectos de la historia cultural independiente de la política o de la economía.

P. Usted estudió Derecho en la Universidad Libre, ¿eso lo hizo paralelo con sus estudios en la ENS?

J. J. u. Mientras estaba de profesor en la Normal Superior y en el Colegio Nicolás Esguerra estudiaba Derecho en la Universidad Libre, pero ya había egresado de la Normal, pero lo que sucedía en verdad es que todavía mi actividad y mi vocación no estaban muy definidas. Siempre pienso en lo relativo que es eso que llaman la vocación, y los esfuerzos que hacen los pedagogos por investigar la vocación de las personas. La vocación depende de un poco de cosas, yo nunca tuve dentro de mis proyectos ser maestro de escuela ni ser profesor y me fue muy bien, me gustó mucho. Desde pequeño yo tenía el proyecto de ser médico, abogado, ingeniero, sobre todo me interesaba la Ingeniería y el Derecho, pero vine a Bogotá y resulté de maestro de escuela. Después entré a la Escuela Normal Superior y fui profesor de colegio y más tarde de universidad. De todas maneras, la formación de derecho me ha sido muy útil hasta hice un intento de ejercer la profesión. Duré seis meses y a los seis meses cerré la oficina porque me horrorizó el ejercicio de esa profesión, y entonces pasé a ser profesor en la Universidad Nacional, cuando Cayetano Betancur me llamó.

Para mí ha sido definitivo el Derecho, tanto que yo le digo a la gente que quiere estudiar historia que tiene que estudiar derecho. De acuerdo

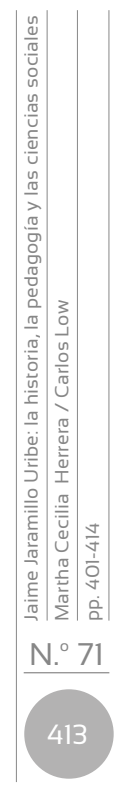


con la opinión de los viejos maestros alemanes del siglo xIx, el historiador tiene que ser jurista, tiene que conocer el Estado y las funciones del Estado. Ese es un vacío que es necesario llenar, al igual que otros, para llegar a ser un buen historiador. Por este motivo a mí no me parece del todo bien lo que se hace hoy día que es pretender formar historiadores desde el pregrado, considero que esa es una carrera de postgrado. Creo que primero hay que hacerse a una formación general de cultura sólida, estudiar derecho, estudiar la organización del Estado, estudiar literatura, hay que aprender lenguas, economía, estadística, en fin, formarse una caja de herramientas. Hoy en día piensan hacer historiadores desde los 18 años con bachilleres que no traen bases sólidas, esto me parece muy difícil. En general considero que todas las carreras sociales y humanas deberían tener niveles de postgrado, partiendo de una formación de lo que se llamó clásicamente filosofía y letras, puesto que son carreras que necesitan una cultura general muy sólida.

P. Pero cuando usted dirigía el Departamento de Historia en la Universidad Nacional, ¿este solo prestaba servicios a las demás facultades?

J. J. U. Inicialmente solo prestaba servicios pero después, en la carrera de Filosofía, establecimos lo que se llamaba la opción en historia y era que a partir de los dos primeros años, los estudiantes podían intensificar cursos en historia o en lingüística sin abandonar los estudios de filosofía. Eso lo llamamos entonces sección y luego se denominó departamento, era como una especie de acercamiento a una formación especializada en los dos años finales, pero conservando el núcleo que se llamaba Filosofía y Letras.

P. Cuando usted se jubiló de la Universidad Nacional en la década del 70 y se vinculó a la Universidad de los Andes, ¿qué nuevos temas desarrolló y actualmente a qué proyectos se dedica?

J. ı. U. Hay que tener en cuenta que durante esos años tuve muchas alternativas. En primer lugar estuve en la Embajada de Colombia en Alemania y realicé algunos viajes. Estuve trabajando, al igual que ahora, en algunos proyectos que no he podido culminar porque me he dispersado por muchos motivos, en parte por tantas conferencias y simposios. ¡Todo eso que es una verdadera calamidad! He estado trabajando en una obra grande sobre el siglo xVIII, sobre el final de la época colonial, 1740 a 1810, que tiene como esfuerzo inicial un ensayo que escribí para la Historia económica de Colombia publicada por Siglo xxı y al cual le voy a dar un giro diferente. También vengo trabajando desde hace algún tiempo otro proyecto que sigue las líneas de un ensayo que publiqué en un libro que se llama La personalidad histérica de Colombia, pero ampliándolas mucho más. Por el momento he publicado artículos por ahí y presentado ponencias en congresos, algunas de las cuales están publicadas en el segundo volumen de Ensayos de historia social. En síntesis, quiero sacar adelante esos dos proyectos y probablemente después escribiré mis memorias. 